\title{
A Rare Case of Anorectal Injury with Ruptured Bladder and Rectum but Normal Anal Sphincter
}

\author{
Mahmoud Aghaei Afshar ${ }^{1 *}$, Foroogh Mangeli² and Akram Nakheai ${ }^{2}$
}

${ }^{1}$ Department of Surgery, School of Medicine, Kerman University of Medical Sciences, Kerman, Iran

${ }^{2}$ School of Medicine, Kerman University of Medical Sciences, Kerman, Iran

\begin{abstract}
Anorectal injuries are rare in children. These injuries mostly occur with two major mechanisms; 1 ) sexual abuse, and 2) penetrating trauma. Coincident injury of rectum and bladder following anorectal trauma has been rarely reported. Here, we describe an anorectal injury in a 15-year-old boy due to falling off a tree leading to anorectal trauma by a stick. After the trauma, the patient experienced hematuria and generalized abdominal pain and tenderness. In anal area inspection, anal sphincter was intact and there were no evidences of trauma. The patient underwent anoscopy and exploratory laparotomy and omentum was extruded. The patient was treated by repair of lacerations and retraction of omentum.
\end{abstract}

Keywords: Anorectal injuries; Bladder laceration; Rectal laceration

\section{Introduction}

Anorectal injures are so rare in children and mostly occur with two mechanisms; 1) sexual abuse, and 2) penetrating trauma [1]. According to different studies, simultaneous rectum and bladder injury following anorectal trauma is rare $[2,3]$.

\section{Case Report}

The patient was a 15-year-old boy, who was referred to the emergency room of Afzalipour Hospital, Kerman because of falling off a tree (a height of three meters) leading to anorectal trauma by a stick (Figure 1). After the trauma, the patient experienced gross hematuria and frequent vomiting. In physical examination, he was pale, with pulse rate of 110 per minute and blood pressure of 90/60 mmHg. Head and neck examination was normal. The patient had tenderness at $11^{\text {th }}$ and $12^{\text {th }}$ left ribs accompanied with generalized abdominal tenderness, guarding and rebound tenderness, which was more severe in left flank and supra-pubic regions. Bowel sounds were reduced. Anal sphincter was intact, without any sign of trauma. In the anal inspection, the only abnormal point was a fat mass with the size of $2 \times 5 \mathrm{~cm}$, extruded from anal canal. The CXR was normal and free sub-diaphragmatic air was not observed (Figure 2). The patient was transferred to the operation room for exploratory laparoscopy. At that time, the $\mathrm{CBC}$ result was as follows: WBC: $14000 / \mathrm{mm}^{3}$ and $\mathrm{Hb}=15.7 \mathrm{~g} /$ dL. Under general anesthesia, rectum examination up to $3 \mathrm{~cm}$ of the anterior wall of rectum and anoscopy were carried out. In anoscopy, a horizontal laceration was observed in the rectum above prostate, where omentum extruded via the laceration into rectum and then anus. The patient underwent exploratory laparotomy with midline incision. In the laparotomy, an almost $3 \mathrm{~cm}$ longitudinal rupture in the anterior wall of rectum and 3 and $4 \mathrm{~cm}$ long ruptures in the posterior wall and dome of bladder respectively were observed. Through the rupture of bladder dome and then the ruptures in the posterior wall of bladder and anterior wall of rectum, omentum progressed toward anus. The two ruptures in the anterior wall of rectum and posterior wall of bladder were retroperitoneal. During the surgery, omentum and rectum were released and retracted into abdominal cavity. The ruptures in the anterior rectal wall and posterior wall and dome of bladder were repaired and finally a colostomy was placed in the proximal part. At last, the patient was discharged with good general condition.

\section{Discussion}

Anorectal injuries are rare in children, and usually occur due to trauma or sexual abuse [1]. Although the reports show that the occurrence of simultaneous rectum and bladder is rare [2,3], according to the studies carried out by Platt and Lynch [3], the most frequent injury following anorectal trauma is rupture of urethra, bladder, vagina, and visceral organs. Sabetay et al. [4] reported rectal injuries following falling off a height. In another study, Kadish et al. [5] stated that most traumas of rectum that occur following falling off a height should not be considered as isolated traumas, and in most cases they are complicated traumas. According to different reports, four factors play role in the prognosis of such traumas; the extent of trauma,

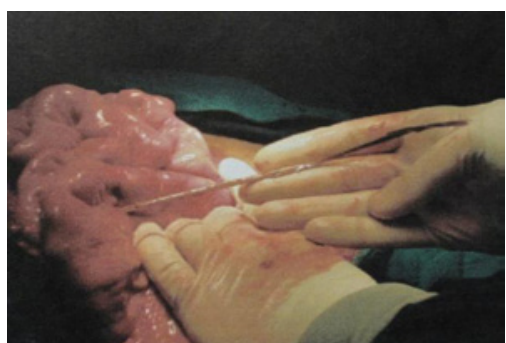

Figure 1: The trauma of rectum by a stick can be observed in the figure.

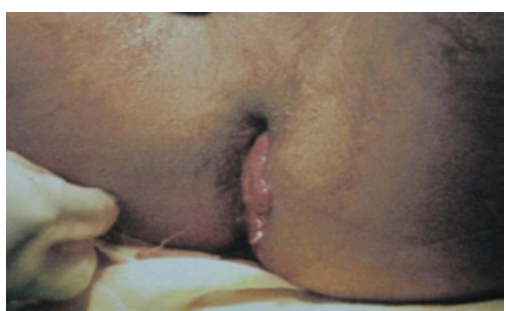

Figure 2: The extrusion of fat mass through anal canal without injuring the sphincter.

*Corresponding author: Mahmoud Aghaei Afshar, Department of Surgery, Shahid Bahonar Hospital, Kerman, P.O. Box: 13185-1678, Tehran, Iran, Tel: +9821 66439463; Fax: +9821 66423304; E-mail: swt_f@yahoo.com

Received September 07, 2012; Accepted September 26, 2012; Published September 28, 2012

Citation: Afshar MA, Mangeli F, Nakheai A (2012) A Rare Case of Anorectal Injury with Ruptured Bladder and Rectum but Normal Anal Sphincter. J Clin Case Rep 2:204. doi:10.4172/2165-7920.1000204

Copyright: (c) 2012 Afshar MA, et al. This is an open-access article distributed under the terms of the Creative Commons Attribution License, which permits unrestricted use, distribution, and reproduction in any medium, provided the original author and source are credited. 
Citation: Afshar MA, Mangeli F, Nakheai A (2012) A Rare Case of Anorectal Injury with Ruptured Bladder and Rectum but Normal Anal Sphincter. J Clin Case Rep 2:204. doi:10.4172/2165-7920.1000204

accompanying traumas, age and general status of the patient, and the interval between occurrence of the trauma and treatment of bacterial contaminations [3-6]. The suggested treatments in such injuries are proximal colostomy, rectal repair (through abdomen or anus), and presacral evacuation, which were carried out in our patient $[2,4,6]$. Finally, it is recommended that in anorectal traumas, careful evaluation of rectum, bladder, vagina, and abdominal visceral organs for occurrence of simultaneous injuries be considered.

\section{Acknowledgement}

The authors would like to thank Farzan Institute for Research and Technology for technical assistance.

\section{References}

1. Ozturk H, Onen A, Dokucu Al, Octu S, Yagmur Y, et al. (2003) Management of anorectal injuries in children: an eighteen-year experience. Eur J Pediatr Surg 13: $249-255$.

2. Tanuma $\mathrm{Y}$, Horita $\mathrm{H}$, Kadono $\mathrm{M}$ (2001) Extraperitoneal bladder rupture secondary to rectal impalement. Int J Urol 8: 634-636.

3. Platt JS, Lynch CM (2003) Rectovaginal injury in a young child. A case report J Reprod Med 48: 889-892.

4. Sabetay C, Purcaru F, Farcas I, Singer I, Ciobanu O (1998) Rectal lesions in children. Clinico-therapeutic considerations of 12 cases. Chirurgia (Bucur) 93 343-347.

5. Kadish HA, Schunk JE, Britton H (1998) Pediatric male rectal and genital trauma: accidental and nonaccidental injuries. Pediatr Emerg Care 14: 95-98.

6. De Rosa G, Peppas C, Vincenti B, Rapicano G, Martino A (1997) Impalement injuries. A clinical case. Minerva Chir 52: 143-148. 